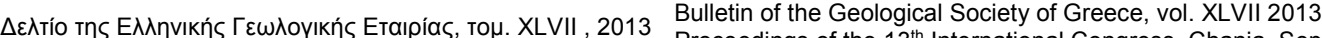

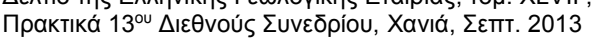

\title{
TAPHONOMICAL OBSERVATIONS ON THE PYGMY HIPPOPOTAMUS SITE IN AGHIA NAPA, CYPRUS
}

\author{
Filippidi A. ${ }^{1}$, Stathopoulou E.T. ${ }^{1}$ and Theodorou G. ${ }^{1}$ \\ ${ }^{I}$ National and Kapodistrian University of Athens, Faculty of Geology and Geoenvironment, \\ Department of Hist.Geology - Paleontology, afilip@geol.uoa.gr,estathop@geol.uoa.gr, \\ gtheodor@geol.uoa.gr
}

\begin{abstract}
In this paper data concerning the taphonomy of the Upper Pleistocene site Aghia Napa in Cyprus is presented. The site is dominated by skeletal material belonging to the pygmy Hippopotamus species Phanourios minor, and consists a littoral rockshelter. The fossiliferous assemblage is spread in a total area of about $72 \mathrm{~m} 2$ and a significantly large number of specimens were collected, indicating the presence of more than 160 individuals at the site. In this paper, we attempt to identify the causes or mechanisms that led to the accumulation of the endemic hippopotamus remains, focusing also on the palaeo-environmental parameters that might had affected the survivorship of the fossils. The taphonomical analysis is also based on parameters, which provide information concerning skeletal element representation and thus survivorship. The study of the skeletal material shows signs of abrasion, cracking and significant fragmentation which are related to the type, size and shape of the skeletal elements. The bone assemblage is interpreted as a result of transportation of the skeletal material from longer or shorter distances in the surrounding area while the impact of man concerning their accumulation is still under discussion.
\end{abstract}

Key words: Phanourios minor, taphonomy, Upper Pleistocene.

\section{Пєрí $\eta \psi \eta$}

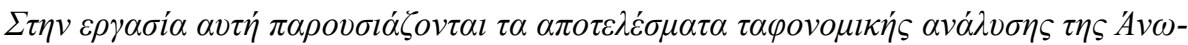

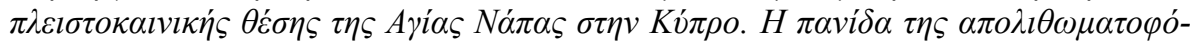

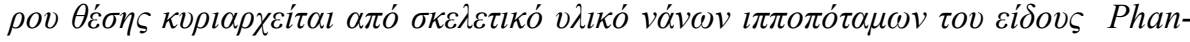

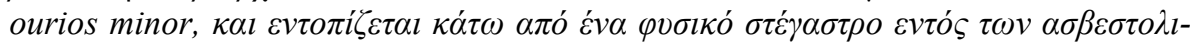

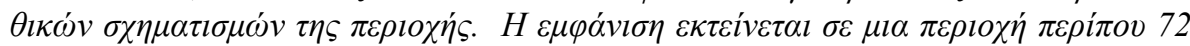

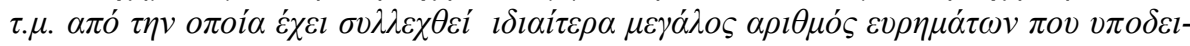

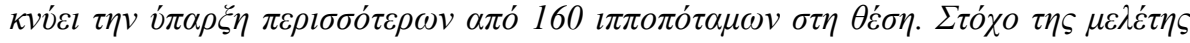

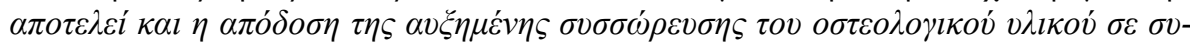

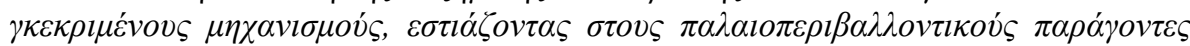

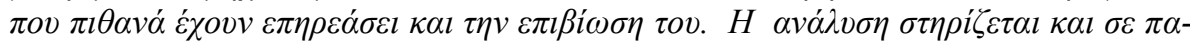

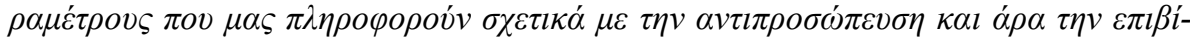

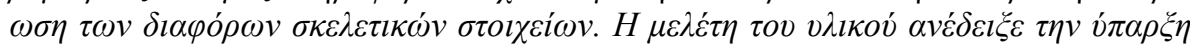

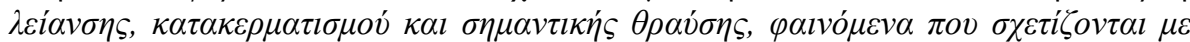

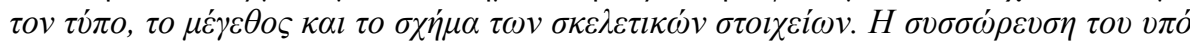

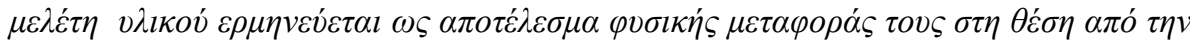

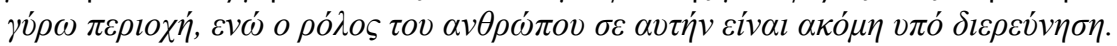

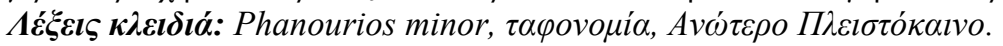

XLVII, No $1-122$ 


\section{Introduction}

The increasing interest of Palaeontologists in taphonomical analysis rendered the latter a necessary and much promising aspect of palaeontological research in fossiliferous sites. It is obvious, that the accuracy and validity of the taphonomical results greatly depend on the appropriate collection of material and data during the excavation. The objective of this paper is to give a full presentation of the findings derived from the Upper Pleistocene fossiliferous site of Aghia Napa in Cyprus till the 2007 excavation and also to provide taphonomical analysis results based on the collected material.

The first excavation at the site of Aghia Napa was realized in 2000 by Ioannis Panayides, from the Geological Survey Department of Cyprus. Since then, six systematic palaeontological excavations have been conducted at the site, under the supervision of Professor G. Theodorou from Athens University and in collaboration with the Geological Survey Department of Cyprus.

Based on the large quantity of skeletal material derived from Aghia Napa, the fauna is dominated by pygmy hippopotami, which have also been described in numerous other sites on the island, e.g. Aetokremnos, Akanthou, Xylophagou, etc (Bate, 1906; Houtekamer and Sondaar, 1979; Held, 1992; Reese, 1995). Except for the material belonging to hippopotamuses, a number of samples have been attributed to other animal groups. With the exception of the carnivore species Genetta plestictoides (Theodorou et al., 2007), most of the latter material has not been thoroughly studied yet. Recently, material belonging to elephants (Stathopoulou et al., 2008) was recovered and is currently being studied. This is the first report of the presence of elephants in Aghia Napa. Work has also been done on the ear bones of the hippo material (Provatidis et al, 2011).

According to Bate (1906) and Houtekamer and Sondaar (1979), Hippopotami and Elephants colonized Cyprus during the Late Pleistocene, starting their journey from Asia Minor and swimming across the shallow Mediterranean waters of that time. The processes of insular dwarfism then began, gradually leading to the reduction of the animals' size in order for them to adapt to their new environment, characterized by hot and dry summers. Furthermore, morphological alterations, such as the development of a more-or-less pig-like foot and the lowering of the eyes and nostrils occurred, due to their adjustment to a more terrestrial mode of life (Houtekamer and Sondaar, 1979).

Through the taphonomical analysis of the Aghia Napa site, we speculate on the mechanisms that led to the accumulation of the hippopotamus remains. We also focus our study on the palaeoenvironmental parameters that affect survivorship of the fossils. The important issue of the coexistence of hippopotamus and man on the island and whether the latter could be responsible for the hippopotamuses' extinction has preoccupied many scientists, including the authors. All data that could possibly lead us towards a theory, was thoroughly examined, in hope of shedding some light on this intriguing matter.

\subsection{The Site of Aghia Napa}

The site of Aghia Napa is located at the South-Eastern part of Cyprus, 500m east of the city of Aghia Napa at an altitude of $25 \mathrm{~m}$ (Figure 1). The bedrock of this area consists of an Upper Cretaceous mélange, which includes bentonitic clays, siliceous - clastic sandstones, lavas, pelagic limestones and red radiolarites. The mélange is followed by the Late Cretaceous - Early Miocene Lefkara Formation consisting of gently dipping pelagic chalks containing irregular lenses and thin beds of porcelaneous chert. These are overlain by the patch reefs of the Aquitanian - Burdigalian Terra Member (Pakhna Formation). The sediment in the hollows between coral colonies is coarse bioclastic debris as well as aggregate grains and lime mud. Coral - dominated patch reefs passed outwards into algal dominated deposits, foraminiferal packstones, grainstones and pelagic carbonates. The fossiliferous beds are found within the remnants of the Miocene coral reefs (Follows et al, 1996).

The numerous fossils are embedded in red clays, deposited in a littoral rock - shelter comprised from limestones. The excavation site covers an area of more than $72 \mathrm{~m}^{2}$, while the fossiliferous 
layers' thickness seems to range between 1 and 1.5 meters (Figure 2). Large limestone pieces from the shelter's roof, found in the sediment, indicate its partial collapse through time.

Despite the various references for the existence of pygmy hippopotamuses in Aghia Napa (Bate, 1906; Reese, 1995), the first palaeontological excavation was realized in the area in 2001. During this excavation, evidence suggesting a previous illicit dig were found. According to local people, it took place 70-80 years ago. The disturbance caused by this dig, led to the creation of relatively loose sediment, which can be distinguished from the cohesive sediment of the undisturbed bonebed. In figures 2 and 3 (vertical sections of site), the richness of fossils in both layers, total range of the excavation site and total depth of the rock-shelter can be observed.

The collected skeletal material has been attributed to the pygmy hippopotamus Phanourios minor (Theodorou, et al., 2004); an endemic species that lived exclusively on Cyprus. Based on the Electron Spin Resonance (ESR) dating of dental material, carried out at the National Centre for Scientific Research "Demokritos" in Athens, by Dr. Y. Bassiakos, the site can be dated back to 11,000-13,500 years B.P. (Theodorou et al., 2007).

\section{Material and Methods}

\subsection{Material}

Until 2007, more than 14,000 specimens of biological origin have been collected at the site. The material belonging to $P$. minor represents the majority of the total specimens, while material from other animal groups, such as carnivores, reptiles and birds, micromammals and marine molluses has been reported. In order to proceed with the taphonomical analysis of the site, the total amount of the findings has been studied, focusing on the pygmy hippopotamus skeletal material.

\subsection{Field Work}

A $9 \times 8 \mathrm{~m}$ grid, divided into $1 \mathrm{~m}^{2}$ excavation squares, was used in order to document the exact position of the findings and all available information was recorded. Detailed drawings, corresponding photographs and sections were also prepared, combined with systematic macroscopic observations. The samples were then removed and the sediment was sieved, in order to collect possible fragments of small objects or bones of small animals.

\subsection{Lab Work}

Lab work included the conservation-preparation, documentation, and assignment, statistical and biometrical analysis of all skeletal material and the weighing of the fragments found throughout the excavation area. Due to the nature of the bone bearing sediments and the excellent state of preservation of the osteological material, the findings were only rinsed with tap water. In several cases, especially when preparing cranial material, acrylic resins such as Paraloid B72 and Polyfilla were used for the adhesion and fixation of the fragmented samples. All samples were macroscopically observed in order to detect any possible repetition of characteristic features.

All hippo material was separated according to element type, age and presence of erosion and then all identifiable bones were separated into three main categories per type (right, left, fragments) and per bone part (proximal, distal, diaphysis). Important taphonomical factors where then calculated. Specifically: The Number of Identifiable Specimens (NISP), the Minimum Number of Individuals (M.N.I.) and the Minimum Number of Elements (MNE) were estimated according to Lyman (1994). The MNI factor represents the total number of elements that can be attributed to whole samples. The Fragmentation Index was estimated for all skeletal elements, according to Lyman (1994); Lyman (2008) and Yeshurun et al. (2007), by comparing NISP to MNE (NISP/MNE). Various other important taphonomic indices (Behrensmeyer and Boaz, 1980; Matthews, 2002; Weissbrod et al., 2005; Broughton et al., 2006; Montalvo et al., 2008) were also calculated. As far as the differences between the bone type distributions are concerned, the Relative Abundance (Ri) was calculated (Andrews, 1990): $\mathrm{Ri}=\mathrm{Ni} / \mathrm{MNI}$ x $\mathrm{Ei}(\mathrm{Ni}$ : number of elements i, Ei: number of 
element $\mathrm{i}$ in the skeleton). The proportions of skeletal elements were evaluated, using the method proposed by Andrews (1990) and Lloveras et al. (2008). This includes the calculation of six indices. The PCRT/CR (Post-cranial / cranial (mandibles, maxilla and teeth), the PCAP/CR (appendicular skeleton elements / cranial material) and PCRLB/CR (long bones / mandibles and maxilla), that compare post-cranial to cranial material, the AUT/ZE (autopodium / zigopodium and stylopodium elements) and the Z/E (zigopodium / stylopodium elements) that compare autopodium to stylopodium and zigopodium elements and the $\mathrm{AN} / \mathrm{PO}$, that compares forelimb to hindlimb elements.

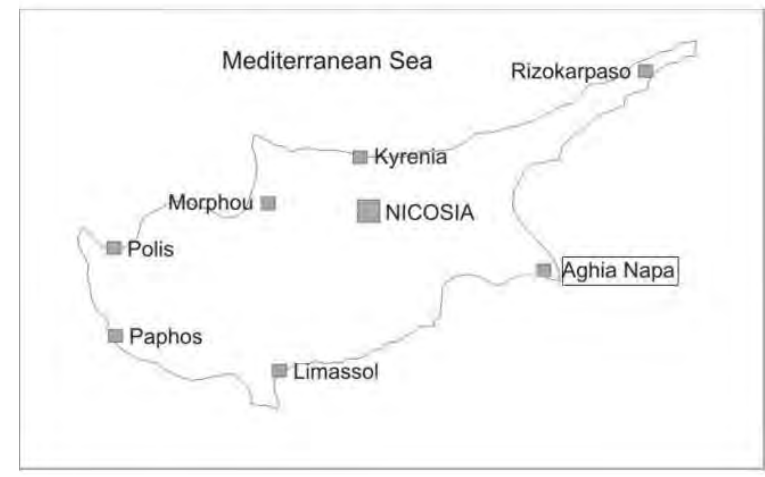

Figure 1 - The island of Cyprus and the location of Aghia Napa.

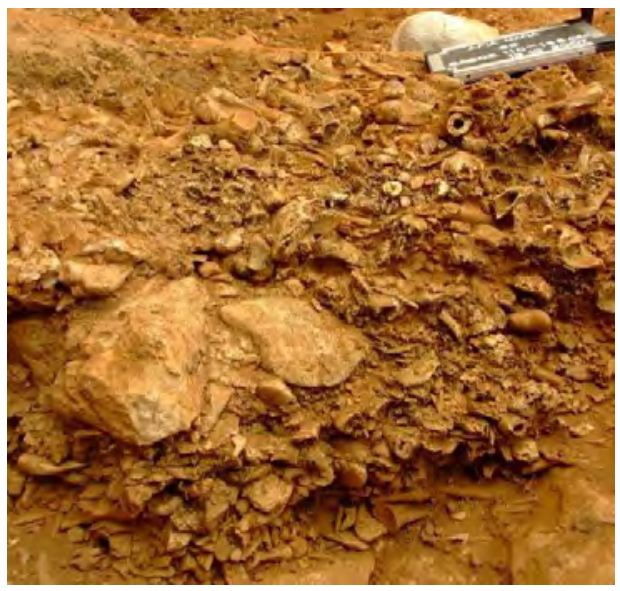

Figure 2 - View of a section of the undisturbed bone beds revealing their high density

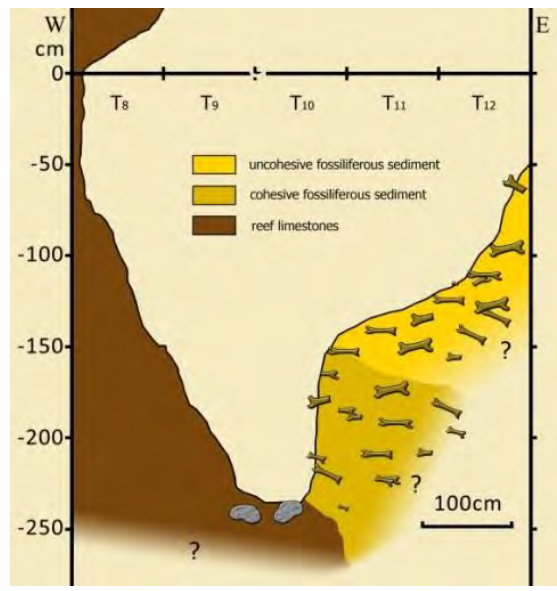

Figure 3 - W-E section of the excavation site.

All the above processing of the drawings and photographs taken during the excavations to define various aspects, such as anatomical relation of bones, despite the fact that during the macroscopic observations made at the excavation area, no such indications were found. Afterwards, a database containing the exact coordinates of all findings was created and used in G.I.S. software, for the projection of the specimens, allowing us to combine different types of information (for example, the distribution of juveniles in the site), in the most efficient way.

\section{Results and Discussion}

\subsection{Skeletal Element Representation}

To date (data from all excavations except for the last one held in 2008), the exact number of specimens derived from the site of Aghia Napa, is 14,299, of which 13,817 have been attributed to pygmy hippopotami (96.6\%). According to the complementary biometrical analysis carried out 
during this study, we were able to confirm the attribution of our material to one species, Phanourios minor (Theodorou et al., 2004). The remaining 3.4\% has been attributed to other animal groups, such as carnivores, reptiles and birds, micromammals and marine molluscs.

In the context of the whole excavated beds, the calculated fossiliferous density (Montalvo et al., 2008) is 817 remains $/ \mathrm{m}^{3}$, a value that verifies an extremely high density assemblage of skeletal material. $8.3 \%$ of the collected hippopotamus specimens consists non-identifiable fragments (mentioned as FNU) and the total NISP per element type is presented in Figure 4 and Table 1. Interestingly, $10 \%$ of the skeletal elements belong to juveniles. The MNI and MNE values are presented in Figure 5 and Table 1, with the right humerus (medial epicondyle of the distal epiphyses) defining the presence of the remains of at least 169 animals at the site.

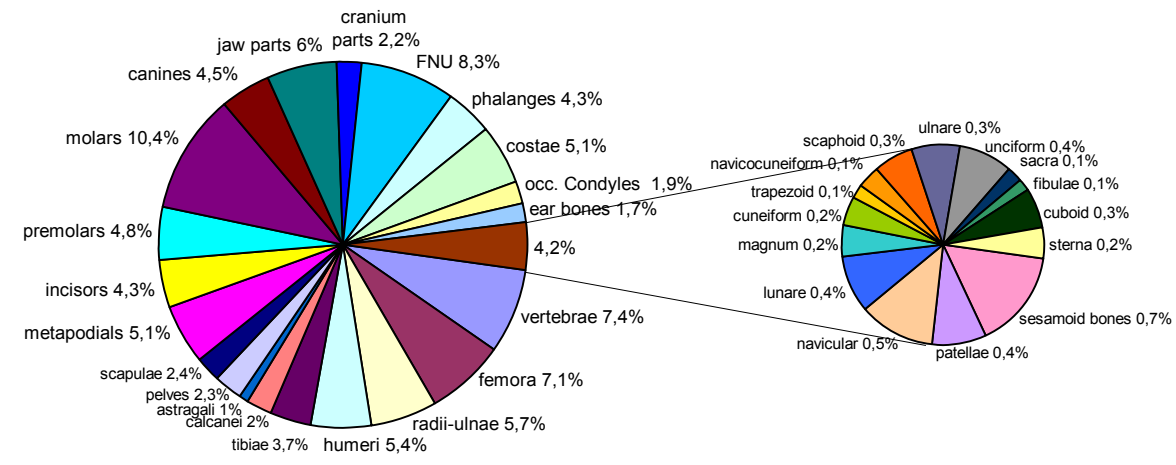

Figure 4 - NISP \% per skeletal element type.

Table 1 - Descriptive data and key taphonomical variables.

\begin{tabular}{cccccc} 
bone type & NISP & MNI & MNE & $\begin{array}{c}\text { Fragmentation } \\
\text { index }\end{array}$ & Ri\% \\
\hline sacrum & 15 & 15 & 15 & 1 & $8,90 \%$ \\
femur & 985 & 129 & 250 & 3,9 & $76,30 \%$ \\
radius-ulna & 782 & 168 & 328 & 2,4 & $99,40 \%$ \\
humerus & 751 & 169 & 337 & 2,2 & $100 \%$ \\
tibia & 505 & 106 & 207 & 2,4 & $62,70 \%$ \\
calcaneum & 275 & 138 & 275 & 1 & $81,60 \%$ \\
astragalus & 142 & 79 & 142 & 1 & $46,70 \%$ \\
pelvus & 324 & 116 & 229 & 1,4 & $68,60 \%$ \\
scapula & 329 & 126 & 248 & 1,3 & $74,60 \%$ \\
ulnare & 46 & 27 & 46 & 1 & $16 \%$ \\
lunare & 54 & 28 & 54 & 1 & $16,60 \%$ \\
navicular & 72 & 39 & 72 & 1 & $23,00 \%$ \\
magnum & 29 & 15 & 29 & 1 & $8,80 \%$ \\
unciform & 49 & 29 & 49 & 1 & $17,20 \%$ \\
cuneiform & 28 & 22 & 28 & 1 & $13 \%$ \\
scaphoid & 38 & 20 & 33 & 1,2 & $11,90 \%$ \\
navicocuneiform & 20 & 13 & 20 & 1 & $7,70 \%$ \\
trapezoid & 13 & 8 & 13 & 1 & $4,70 \%$ \\
cuboid & 37 & 20 & 37 & 1 & $11,80 \%$ \\
patella & 50 & 27 & 50 & 1 & $16 \%$ \\
occipital & 269 & 145 & 264 & 1,01 & $85,80 \%$ \\
petrus & 239 & 57 & 106 & 2,3 & $33,70 \%$ \\
fibula & 11 & 7 & 11 & 1 & $4,10 \%$ \\
\hline
\end{tabular}

XLVII, No $1-126$ 


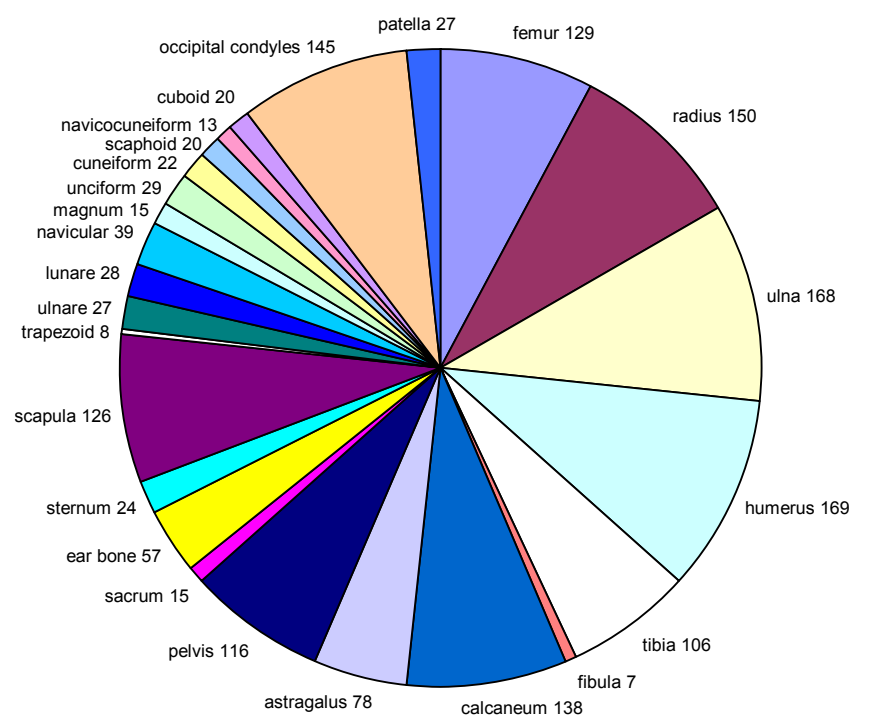

Figure 5 - MNI representation of the Hippo skeletal material.

The material was studied as two separate categories: cranial and post-cranial, which represents $36 \%$ and $64 \%$ of the total respectively (Figure 6). Despite the great amount of teeth that has been collected, the post-cranial material is significantly richer. The studied cranial material $(4,951$ elements), includes cranium parts $(6 \%)$, jaw parts $(17 \%)$, ear bones $(5 \%)$, occipital condyles $(5 \%)$ and teeth (incisors, canines, premolars and molars) (67\%). Teeth are the most common cranial material (3,316 specimens). The detailed description of teeth is given in Figure 7, in which it is obvious that the proportion of the teeth present does not coincide with the expected if all teeth remained in situ. Molars seem to be the most enriched whole tooth type, a fact that can be explained by the low percentage of fragmentation. The same observation applies to the premolars, although the total amount of the specimens is much less than the expected. Their small size could be the explanation to their low representation, which combined with transportation led to their loss. Concerning the canines and the incisors, they present a high percentage of fragmented elements, probably due to their shape. The layer of enamel, which covers canines, might be the reason for their toughness, hence, their high degree of survivorship.

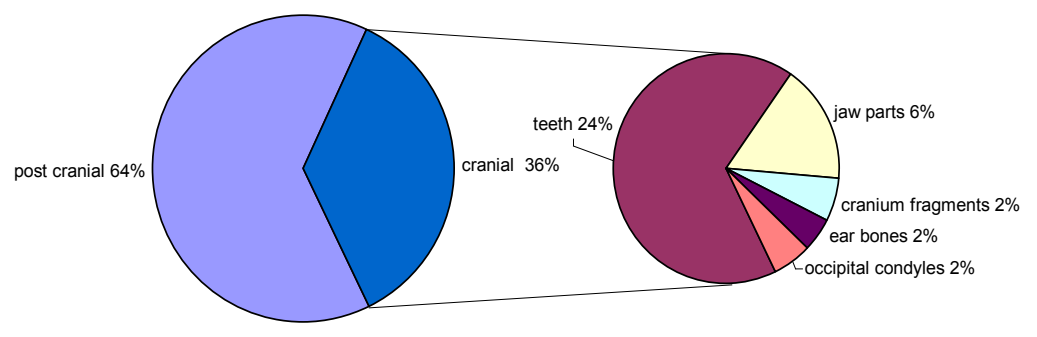

Figure 6 - Proportion of cranial and post-cranial hippo material and representation of cranial elements, at the Aghia Napa site.

In Figure 8 and 9, one may observe an analytical description of the forelimb and hindlimb, respectively. In both figures, elements belonging to the large sized bones appear in greater quantities than the small ones but on the other hand only a small percentage of those represent complete remains, contrary to autopodium elements. 


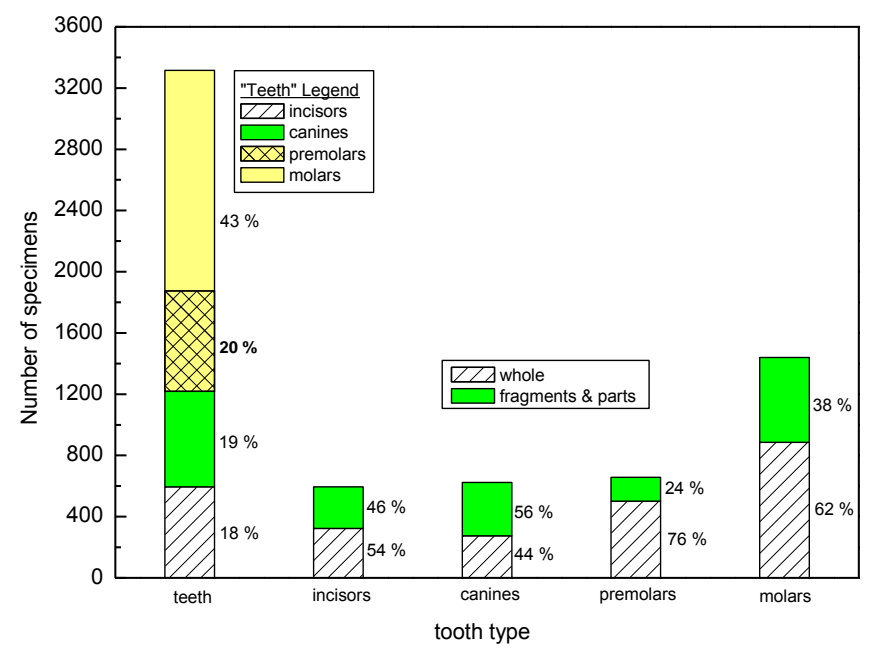

Figure 7 - Representation of whole and fragmented teeth in Aghia Napa. The amounts given in the first column from the left concern whole specimens.

Table 2 - Proportion of different parts of the skeleton.

\begin{tabular}{cc} 
Indices & Values \\
\hline PCRT/CR & 1,25 \\
PCRAP/CR & 1,22 \\
PCRLB/CR & 5,7 \\
AUT/ZE & 0,8 \\
Z/E & 0,9 \\
AN/PO & 1,27 \\
\hline
\end{tabular}

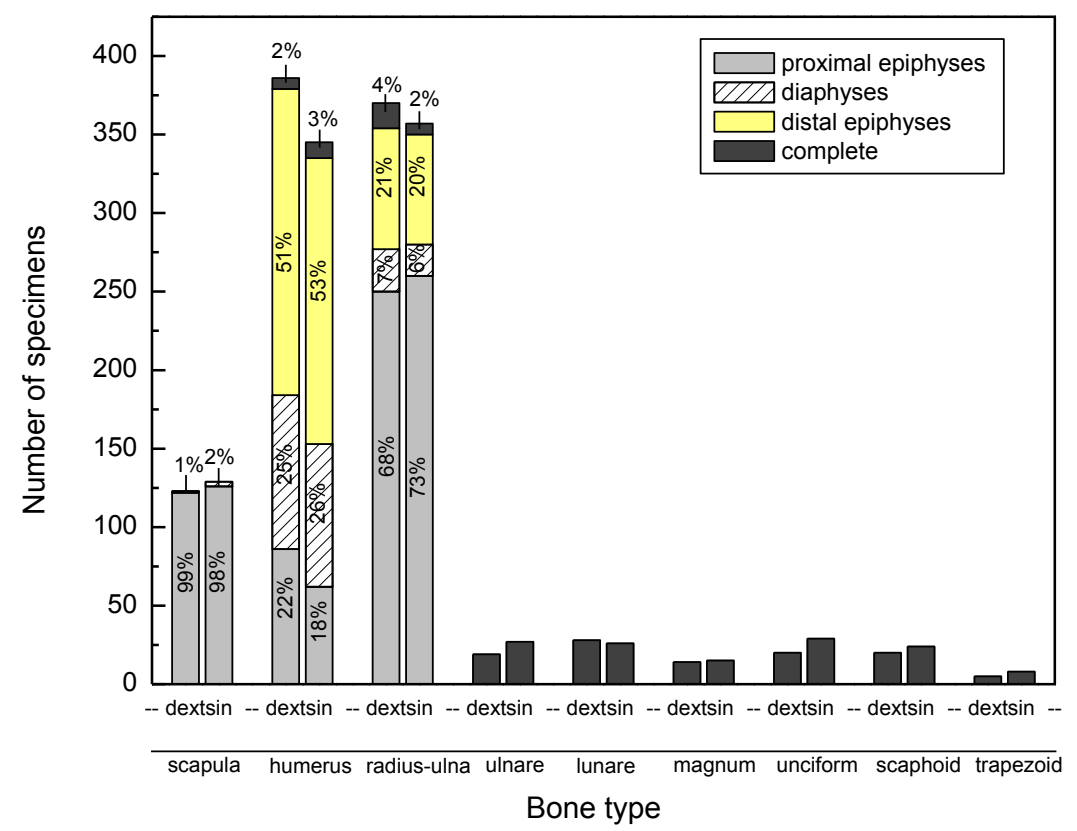

Figure 8 - Numeric representation of the skeletal material of the fore limb.

XLVII, No $1-128$ 


\subsection{Element Fragmentation and Survivorship}

According to the proportions of skeletal elements evaluated (Andrews, 1990; Lloveras et al., 2008) (Table 2), the PCRT/CR, the PCAP/CR and PCRLB/CR indicate a deficiency of cranial material, especially in the case of PCRLB/CR. Concerning the loss of distal limb elements, the AUT/ZE and the Z/E reveal the systematic loss of smaller (and lower) limb elements when compared to the larger (and upper) bones. The last index used, AN/PO shows the greater survival of the anterior skeletal elements. These results are consistent to the data, given in figures 8 and 9 .

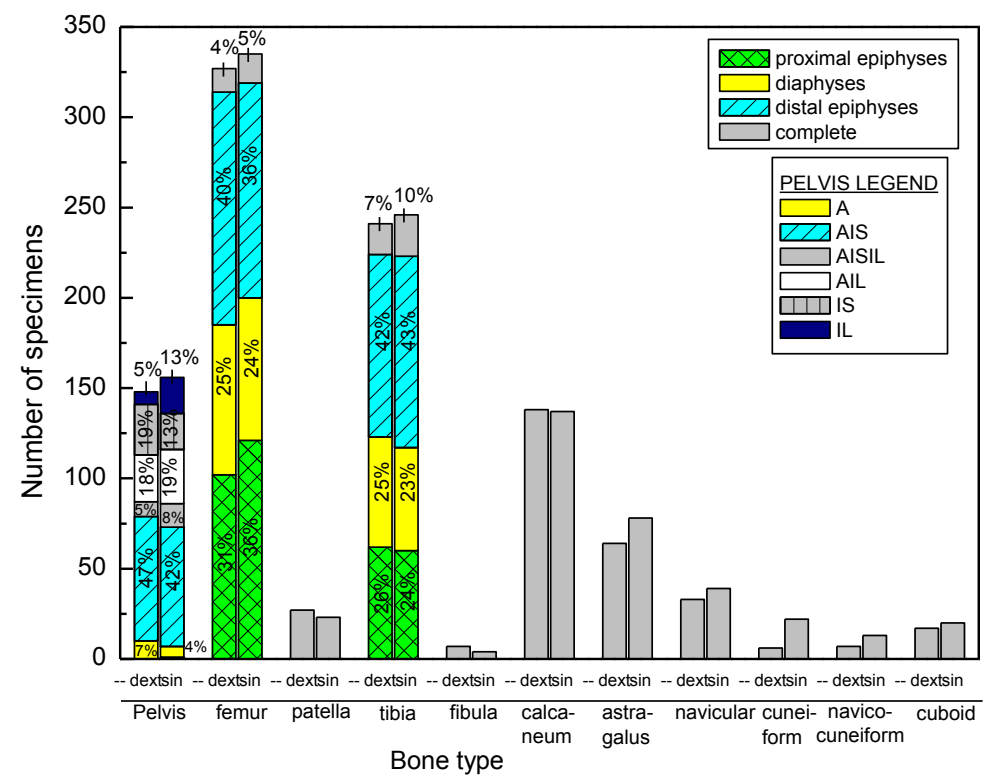

Figure 9 - Numeric representation of skeletal elements of the hind limb. Pelvis parts: A: acetabulum, AIS: acetabulum + ischium, AISIL: acetabulum + ischium + ilium, AIL: acetabulum + ilium, IS: ischium, IL: ilium ( Lloveras et al., 2008).

The results and values concerning the Fragmentation Index, estimated for all skeletal elements, are presented in Figure 10 and Table 1. A fragmentation of one means that the NISP and MNE are equal, and thus no fragmentation has occurred. Increases in the index, suggest greater breakage.

Our own results prove once again that the bigger the skeletal element, the less resistant to fragmentation it appears to be. As seen in Figure 11, the Relative Abundance values indicate that the large/long bones appear more abundant than small/compact bones. At this point we would like to point out the effect of the previously mentioned illicit dig, on such indices. Fragmentation of material has been observed to be importantly increased by this disruption. Thus, we have two types of fragmentation, that of the disrupted material (by the illicit dig) and that of the undisrupted material. Unfortunately these could not be statistically differentiated.

\subsection{Macroscopical Observation of Skeletal Elements}

\subsubsection{Abrasion}

During the excavations, an important amount of samples with signs of abrasion were observed and collected. This feature was considered to be important, as it might help explain the accumulation mechanism that has occurred through time. Transportation of skeletal material by water and wind or even weathering due to exposure in situ and soil flow, is known to have caused such phenomena. Various degrees of abrasion where observed, but regardless of this, only total percentages of abraded remains per bone type were estimated. The total amount of skeletal elements exhibits $22.6 \%$ abrasion. In Figure 12, it becomes obvious that the more fragmented the 
elements, and thus containing more broken and irregular surfaces, the less resistant to abrasion they become. Furthermore, a comparison between the abrasion of adults and juvenile individuals was made (Figure 13), and greater presence of abrasion in the latter group was observed. The distribution of the abrasion in juveniles, follows the general pattern presented in Figure 12, but appears at a larger extent, possibly due to the extra surfaces created by the unfused epiphyses. Juvenile bones, due to their small size were possibly exposed to similar conditions throughout their extent, thus presenting a more homogenous abrasion.

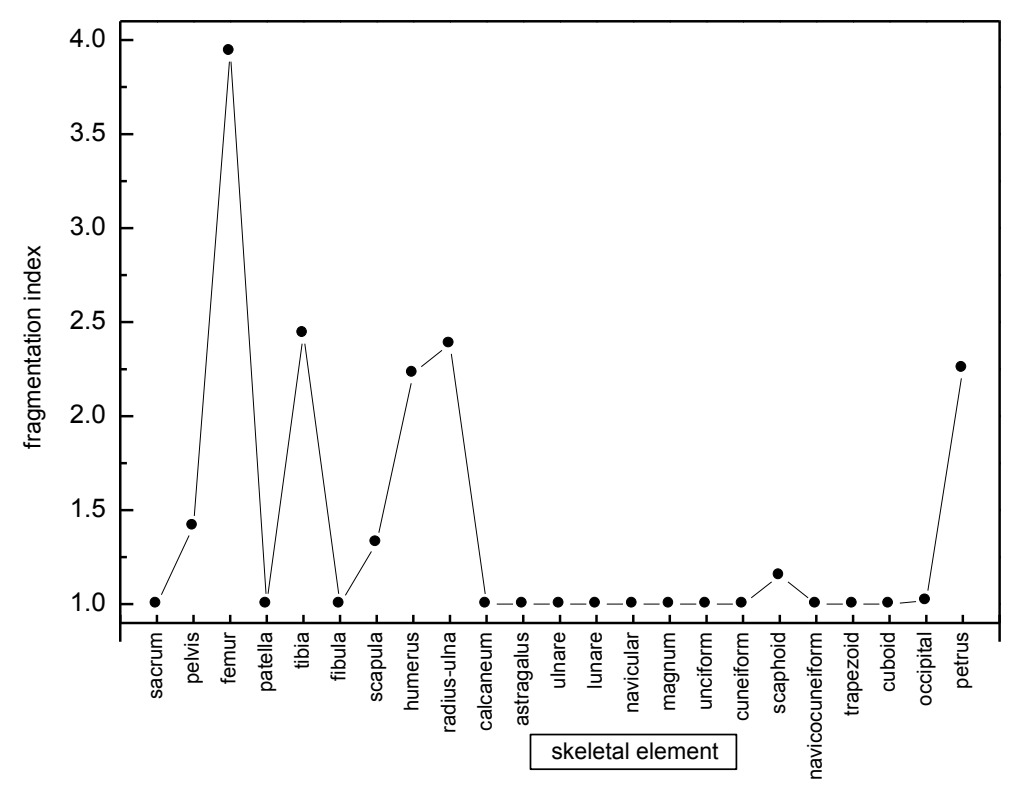

Figure 10 - Comparison of the fragmentation index for each bone type (NISP/MNE).

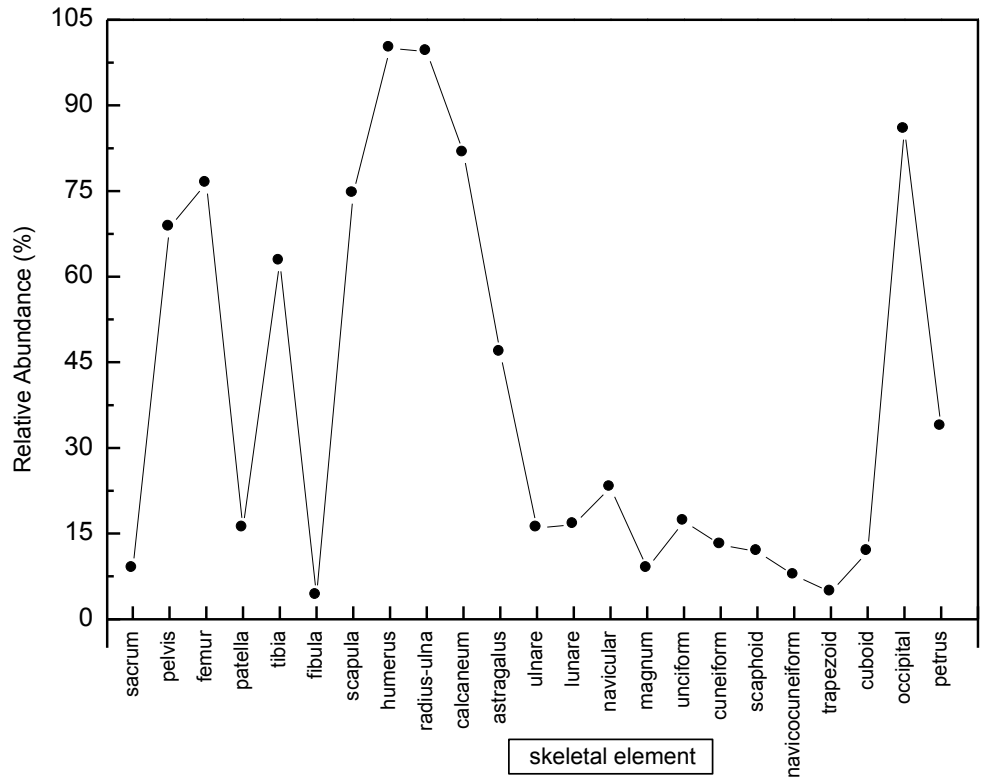

Figure 11 - The Relative Abundance for each bone type. 


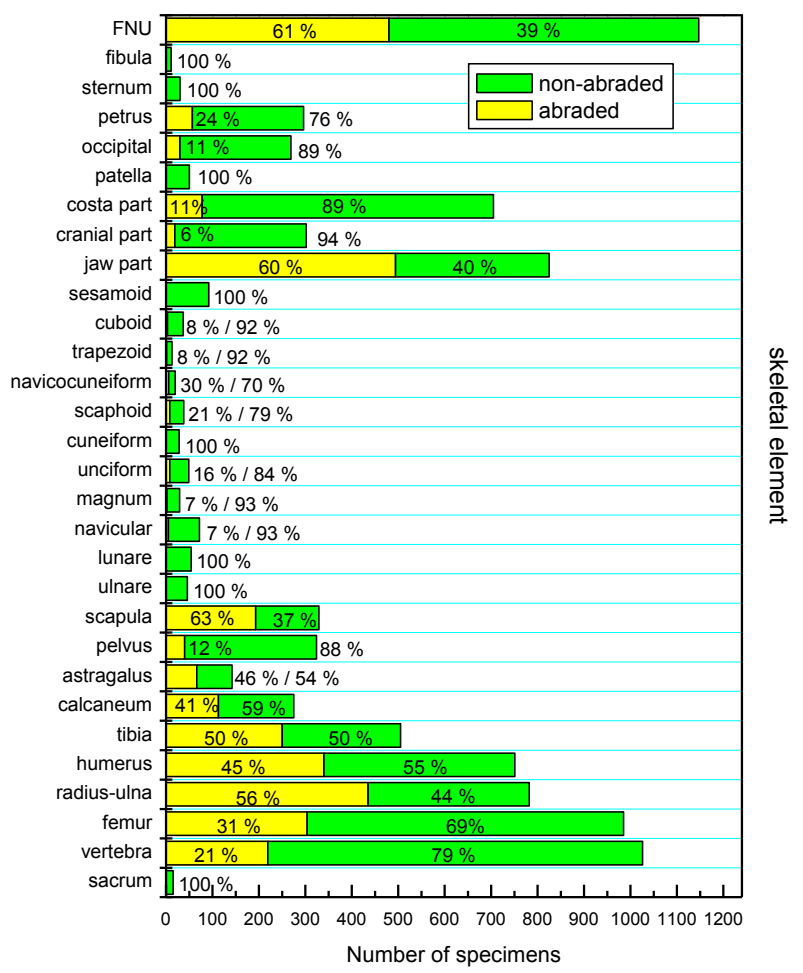

Figure 12 - Numeric representation of the skeletal elements' abrasion.

\subsubsection{Surface Marks and Features}

A preliminary study of the skeletal remains' surface has begun, concerning signs resulting from biological activity and post-depositional procedures, such as the dissolution and precipitation of calcium carbonate from the cave walls.

Biological marks, such us tooth marks and gnawing have not yet been verified, while signs of root development can be observed in certain cases. Further study on the above is already in progress, but the restricted appearance of these phenomena till now, does not allow the extraction of important conclusions. Post depositional precipitation of calcium carbonate was identified either as crust development on the surface of bones and teeth, or as the formation of extremely compact bone breccias with a calcareous matrix. This calcareous material was produced by the partial dissolution of the limestone cave walls, due to the climatic conditions of the area, probably following fluctuations of seasonal humidity. In a few cases, the above climatic variations have also led to the superficial erosion of the bones, which is limited to specific areas of the fossils, probably those exposed to the atmospheric conditions. This appears as a system of mesoscopic cracks, which are often responsible for the exfoliation of the bones.

\subsubsection{Cracking}

Cracking of the fossil long bones seems to occur in two types. The first can be described by multiple fractures, limited to the surface of the bone, indicating extensive pressure either from the overlaying sediments and fallen rocks or the weight of passing animals and men. The second type includes larger fractures that may some times lead to the separation of the bone into parts, often accompanied by their shifting. This type might have occurred following natural processes (which are described in the first case) including diagenetic procedures combined with regional movement of the non cohesive sediment, but also due to the significant disturbance of the site from recent human activity, including the mentioned illicit dig. 


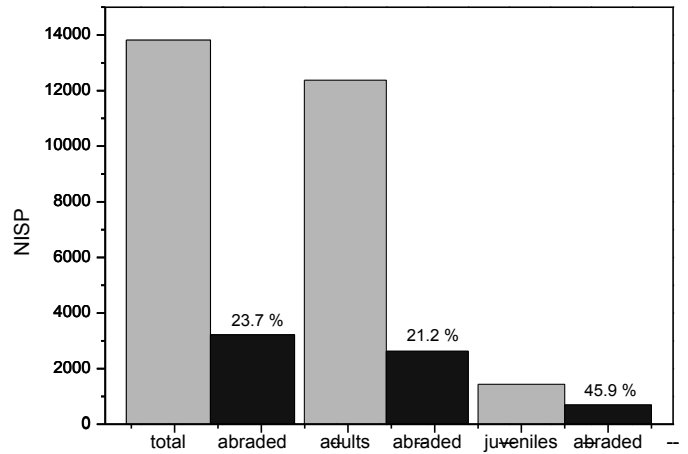

Figure 13 - Comparative presentation of the abraded adult and juvenile individuals.

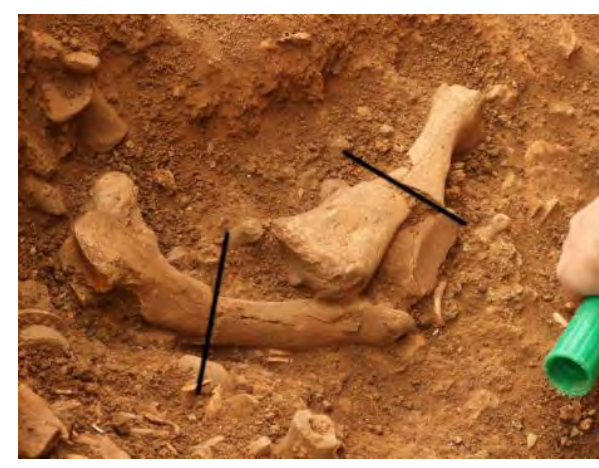

Figure 14 -Fragmentation of bones in a non parallel maner.

\subsection{Diagenesis of Skeletal Material}

As part of our taphonomical analysis, previous results on the diagenesis of the skeletal material were also taken under consideration (Stathopoulou, 2005; 2008). According to these, the skeletal material of the fossiliferous site is characterized by numerous diagenetic changes in bone, especially in terms of histology. This is mainly expressed as a result of microbial activity, leading to the partial destruction of this microstructure. Dentine reacts similarly to bone, while enamel is the hardest and less vulnerable to diagenetic processes. Alterations of our material also concerns crystallinity, chemistry and structural parameters of the biomaterial as well as permineralization. All results suggest a wet and warm climate, capable of allowing phenomena such as microbial activity and the type of preservation observed in Aghia Napa.

These have also shed light on the important issue of black coloured bones and teeth found at the site (Stathopoulou, 2005; 2008; Stathopoulou, et al., 2004). Similar occurrences in other pygmy hippo sites in Cyprus have been reported as evidence of fire, based on macroscopic observations on the material, either caused by direct burning by man, or as a result of human activity above the fossiliferous horizons (hearths) (Simmons, 1999). The extensive study of the the black bones proved that the colouration of the currently studied material is a result of staining by $\mathrm{Fe}$ and $\mathrm{Mn}$ oxides and not of burning. No correlation to the presence and effect of man on the material can be implied by these findings till now (Stathopoulou et al., 2004).

\subsection{Theories on the Taphonomical History of Aghia Napa}

As described in detail above, the fossiliferous site in Aghia Napa is characterized by an extremely dense accumulation of hippo skeletal remains. The results of the taphonomical analysis reinforce the macroscopic observation, concerning the absence of any significant anatomical relation between the findings' distribution. Attempting to limit the effect of the illicit-dig on the results of our study, the unidentified bone and tooth fragments found throughout the excavation, were weighed. By doing this, we were able to observe the fragments' distribution in every excavation square and at different depths (distribution per $10 \mathrm{~cm}$ ). The division chart, containing the data for the depth of 70-80 cm defined the upper limit of the undisturbed fossiliferous layer approximately at that depth (Filippidi and Mourkou, 2007).

Based on the calculated taphonomical parameters and indices, we are led to the following theories. Given the extremely high MNI, and the great density of fossils in relation to the small total excavating area, we can assume that this assemblage was the result of a gradual deposition of hippopotamus' skeletal material. The presence of various size groups of both adult and juvenile material, suggests that the living hippopotamuses were subjected to environmental stress, caused by either climatic changes and reduction of available food supplies or the possible impact of man, given the absence of other large predators, which eventually led to their death and accumulation at 
the site. Reviewing the results of the fragmentation index (Lyman, 1994) and the indices concerning the proportion of skeletal elements (Andrews, 1990; Lloveras et al., 2008), one may conclude that there has been transportation of the material at some extent. Specifically, the relative abundance of the autopodium elements compared to that of the stylopodium and zygopodium elements, combined with the highly fragmented cranial material suggests that most of the fossils found at the site have been transported from the surroundings. On the other hand, the full representation of all skeletal elements implies that the distance covered must have been relatively limited and that in some way; the rock shelter represented the last obstacle during their journey.

According to Behrensmeyer and Boaz (1980), the ratio of isolated teeth to vertebra can provide us with the characterization of a fossil assemblage as being hydrodynamically biased before burial. In the case of Aghia Napa, this index (teeth/vertebra=3,4) suggests that isolated teeth are more frequent than vertebra, although they should appear in similar numbers if the association had a complete representation of the skeletal elements. This agrees with the results derived from relevant indices mentioned above. Furthermore, the complete absence of anatomical relation observed at the site in the undisturbed layers, proves the transportation of the material and can be explained as a result of the disarticulation of the hippopotamus skeletons before burial and before or/and during transportation. The extent of the transportation is also unknown to us, as the degree of abrasion and representation of the various skeletal elements differs greatly. The large quantity of fragments found throughout the bone beds, present different degrees of abrasion, indicating that fragmentation preceded the processes of transportation and burial. This allows their discrimination from the more recent fragments, produced during the illicit dig or even the excavation periods. The transportation mechanism might still be active, as the surficial erosion of the landscape is a continuous procedure.

The thorough observation at the excavation site, combined with the study of the drawings and photographs led us to the conclusion that findings' position in the extremely rich undisturbed fossiliferous layer do not follow a certain pattern. Having examined the direction of the long bones, they do not appear parallel even in the same layers. The random orientation of the bones cannot be attributed to a single factor, such as sediment flow or even the action of the drainage network. The same can be noted in the case of the cracking of the bones (Figure 14).

According to the results of the documentation of the materials position by GIS, we can also point out the absence of a specific accumulation of the skeletal remains based on their type, shape, size or weight. In Figure 15, this can be observed in the case of various adult bone types and in addition most of the findings seem to be gathered near the rock-shelters' walls.

Summarizing, the degree of the fragmentation, abrasion and representation of skeletal elements, throughout the site does not allow the attribution of the assemblage to a thanatocenosis. Our data lead to the conclusion that the present condition of the fossil assemblage has resulted from the transportation of the skeletal remains some time after their death, unknown to us, and their deposition. Due to its location, the roof-shelter might have acted as a natural trap for either transported skeletal material, or even for some of the actual animals themselves, in their seek for drinking water (Hadjisterkotis and Reese, 2008). In any case, this is not opposed to the theory that hippopotamuses might have lived in or nearby the cave at some time.

We must also point out the possibility of transportation of a certain amount of the material by scavenging animals or even by man. Despite the fact, that the recovery of material belonging to Genetta plestictoides from the hippopotamus fossiliferous beds, is considered to be indirect evidence of the coexistence of hippopotamuses and man on the island; no specific evidence of their coexistence has been reported in Aghia Napa. Also, some of the marine molluscs found at the site, cannot be attributed to transportation by birds. Still, although these are indications for the presence of man at the site, they are far from being proof of their co-existence and their interaction with the hippopotamuses. We have also not found any tool marks, tools or proof for the use of fire in the cave yet. 
The site of Aghia Napa is indisputably a fossil assemblage of significantly controversial features and thus of taphonomical interest. We consider to have only attempted to reveal a part of the total picture and intend to continue our study in the future.

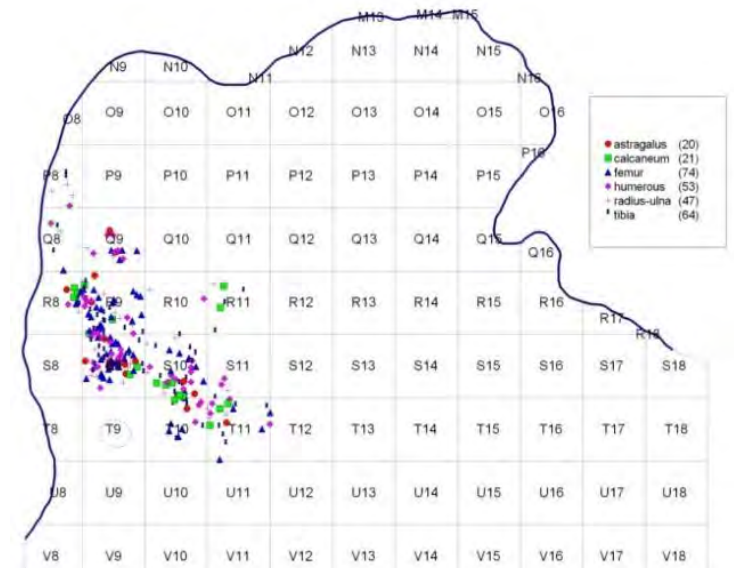

Figure 15 - Spatial projection of specific adult bone types (femur, tibia, astragalus, calcaneum, humerus, radius-ulna) from the undisturbed layer.

\section{Acknowledgments}

Acknowledgments are owed to the General Secretariat for Research and Technology (Greece), the Special Account for Research Grants of Athens University and the Geological Survey Department of Cyprus (UOA programs 70/3/6050, 70/3/6017, 70/3/7093, 70/4/3670) and the Municipality of Aghia Napa for funding this study. We would also like to thank I. Panayides for giving us the opportunity to study this material and Lecturer N. Evelpidou for the spatial and statistical analysis of the geographical data in a GIS environment.

\section{References}

Andrews P. 1990. Owls, Caves and Fossils, Chicago; IL: Natural History Museum and University of Chicago Press, $231 \mathrm{pp}$.

Bate D.M.A. 1906. The pygmy hippopotamus of Cyprus, Geological Magazine, 3(6), 241-245.

Behrensmeyer A.K. and Dechant B. 1980. The recent bones of Amboseli Park, Kenya, in relation to East African paleoecology, in Behrensmeyer, A.K. and Hill, A.P., (eds), Fossils in the Making, Vertebrate Taphonomy and Paleoecology. 72-92, Chicago: University of Chicago Press, $350 \mathrm{pp}$.

Broughton M.J., Cannon, I.V., Arnold S., Bogiatto J.R. and Dalton K. 2006. The Taphonomy of Owl-Deposited Fish Remains and the Origin of the Homestead Cave Ichthyofauna, Journal of Taphonomy, 4(2), 69-95.

Filippidi A. and Mourkou M. 2007. Taphonomical Observations on Pygmy Hippopotamuses at Aghia Napa, Cyprus, using G.I.S. software, Unpublished undergraduate thesis, University of Athens, pp.134.

Follows E.J., Robertson A.H.F. and Scoffin T.P. 1996. Tectonic controls of Miocene reefs and related carbonate facies in Cyprus, in Fransee, E.K., Esteban, M., Ward, C.W. and Rouchy, J.-M (eds), Models for Carbonate Stratigraphy from Miocene Reef Complexes of Mediterranean Regions, 5, 295-316.

Hadjisterkotis E. and Reese S.D. 2008. Considerations on the potential use of cliffs and caves by the extinct endemic late Pleistocene hippopotami and elephants of Cyprus, European Journal of Wildlife Research, 54: 122-133. 
Held S. 1992. Pleistocene fauna and Holocene humans: A gazetteer of palaeontological and early archaeological sites on Cyprus, Studies in Mediterranean Archaeology, Monographs, No 95, Astrom Editions, 195 pp.

Houtekamer J.L. and Sondaar P.Y. 1979. Osteology of the forelimb of the Pleistocene dwarf Hippopotamus from Cyprus with special reference to phylogeny and function, Proceedings Koninklijke Nederlande Akademie van Wefenschappen (B), 82(4), 411-448.

Lloveras L., Moreno-Garcia M. and Nadal J. 2008. Taphonomic study of leporid remains accumulated by the Spanish Imperial Eagle (Aquila adalberti), Geobios, 41, 91-100.

Lyman L.R. 1994. Vertebrate Taphonomy, Cambridge, Cambridge Unversity Press, 524pp.

Lyman R. L. 2008. Quantitative Paleozoology, Cambridge, Cambridge University Press, 345 pp.

Matthews T. 2002. South African Micromammals and Predators: Some Comparative Results, Archaeometry, 44(3), 363-370.

Montalvo C.I., Melchor R.N., Visconti G. and Cerdeño E. 2008. Vertebrate taphonomy in loesspaleosol deposits: a case study from the Miocene of central Argentina, Geobios, 41, 133143.

Provatidis C. G., Theodorou E.G. and Theodorou G. E., 2011. Computed Tomography and $\mathrm{CAD} / \mathrm{CAE}$ methods for the study of the osseous inner ear bone of Greek Quaternary endemic mammals, Mediterranean Archaeology and Archaeometry, 11(2), 121-127.

Reese D.S. 1995. The Pleistocene vertebrate sites and fauna of Cyprus, Geological Survey Department Bulletin, 9, 230.

Simmons A.H. 1999. Faunal extinction in an island society, Pygmy hippopotamus hunters of Cyprus, New York, Kluwer Academic, 381 pp.

Stathopoulou E., 2008. Contribution to the Study of the Internal Micromorphology and Fossilization of Cenozoic Vertebrates by Radioanalytical Technique, Phd thesis, GAIA, No 19, University of Athens, $369 \mathrm{pp}$.

Stathopoulou E. T. 2005. First results on the fossilization of Dwarf Hippo skeletal remains from Aghia Napa, Cyprus, Monografies de la Societat d'Historia Natural de les Balears, 12, 319-324.

Stathopoulou E. T., Theodorou G., Panayides I., and Bassiakos Y. 2004. Diagenesis of bone and colouration: the example of Aghia Napa, Cyprus, Proceedings of the $5^{\text {th }}$ International Symposium on Eastern Mediterranean Geology, Thessaloniki, 14-20 April, 1: 347-350

Stathopoulou E., Filippidi A., Theodorou G. and Panayides I. 2008. Preliminary study of the first possible elephant remain at Aghia Napa, Cyprus, $5^{\text {th }}$ Symposium on Archaeometry of the Hellenic Society of Archaeometry, Athens, 8-10 October, Book of Abstracts.

Theodorou G., Panayides I. 2003. First data on the fossil hippopotamus from Agia Napa Cyprus, International Symposium "Insular Vertebrate evolution: The palaeontological approach", Palma de Mallorca, Spain, 16-20 September, pp 65.

Theodorou G., Panayides I., Stathopoulou E., Papaspyropoulos C., Agiadi K. and Tsolakis E. 2004. Remarks on the endemic fossil Hippopotamus from Aghia Napa (Cyprus), Proccedings of the $5^{\text {th }}$ International Symposium on Eastern Mediterranean Geology, Thessaloniki, 14-20 April, 1: 355-358.

Theodorou G., Roussiakis S.I., Athanassiou A., Giaourtsakis I. and Panayides I., 2007. A late Pleistocene endemic Genet (Carnivora, Viverridae) from Aghia Napa, Cyprus, Bulletin of the Geological Society of Greece : Proceedings of the $11^{\text {th }}$ International Congress, vol. XXXX, p. 201-208.

Weissbrod L., Dayan T., Kaufman D. and Weinstein-Evron M., 2005. Micromammla taphonomy of el-Wad Terrace, Mount Carmel Israel: distinguising cultural from natural depositional agents in the Late Natufian, Journal of Archaeological Science, 32, 1-17.

Yeshurun R., Marom, N. and Bar-Oz G. 2007. Differential Fragmentation of Different Ungulate Body-Size: A Comparison of Gazelle and Fallow Deer Bone Fragmentation in Levantine Prehistoric Assemblages, Journal of Taphonomy, 5(3), 137-148. 